\title{
Geotechnical Research: Referees 2019
}

The following is a list of referees who have reviewed papers for Geotechnical Research between 1 January 2019 and 31 December 2019. The Institution of Civil Engineers is very grateful for their assistance.

We are continually looking for suitable reviewers for papers submitted to Geotechnical Research. Papers published in the Geotechnical Research must be submitted to at least two independent referees to judge accuracy, style, impact, importance and interest.

Hugo Acosta-Martinez

Isaac Ahenkorah

David Airey

M. M. Younus Ali

Konstantinos Andrianopoulos

Afshin Asadi

Abdul Baki

Nezam Bozorgzadeh

Cheng Chen

Siau Chen Chian

Ovidiu Craciun

Andrea Diambra

Daniela Giretti

Laura Govoni
Fadi Haddad
Michael Hatch
Jia He
Ashraf Hefny
Atsushi lizuka
Asif Iqbal
Piratheepan Jegatheesan
Jian Ji
Md Rajibul Karim
Benoît Latapie
Chenhui Lee
Siew-wei Lee

If you are interested in reviewing articles on any topic related to geotechnical research, please submit your name, qualifications or CV, and areas of expertise. We are in need of individuals who will agree to review papers in a timely fashion (within 3 to 4 weeks of receipt) and provide confidential feedback to the Editorial Advisory Panel concerning the quality of the paper and any suggested revisions that would be appropriate.

If you are such a person, please contact Sam Hall (tel.: +44 (0)207 665 2450; e-mail: sam.hall@ice.org.uk) for more information on the referee process.

Weichao Li

Suched Likitlersuang

Seyed Morteza Marandi

Svetlana Melentijevic

Abbas Mohajerani

Nor Zurairahetty Mohd Yunus

Rachel Monteith

Khoi Nguyen

Kaveh Ostad-Ali-Askari

Dalim Paul

Alexandre Pinto

Hongyu Qin

Hossein Safehian
Ranjan Satyamurthy

Md. Mahmud Sazzad

Kamaljit Singh

Stefano Stacul

Cherdsak Suksiripattanapong

Dariusz Wanatowski

Jingan Wang

Juan Wang

Lei Wang

Yang Xiao

Yunming Yang

Katarzyna Zabielska-Adamska 